\title{
Partially defatted black soldier fly larva meal inclusion in piglet diets: effects on the growth performance, nutrient digestibility, blood profile, gut morphology and histological features
}

\author{
Ilaria Biasato1, Manuela Renna², Francesco Gai ${ }^{3}$, Sihem Dabbou², Marco Meneguz ${ }^{2}$, Giovanni Perona ${ }^{4}$,
} Silvia Martinez ${ }^{5}$, Ana Cristina Barroeta Lajusticia ${ }^{6}$, Stefania Bergagna ${ }^{7}$, Luca Sardi $^{8}$, Maria Teresa Capucchio ${ }^{2}$, Enrico Bressan ${ }^{1}$, Andrea Dama', Achille Schiavone ${ }^{2,3^{*}}$ (D) and Laura Gasco ${ }^{1}$

\begin{abstract}
Background: The aim of this trial was to investigate the effects of different inclusion levels of a partially defatted black soldier fly (BSF, Hermetia illucens L.) larva meal on the growth performance, nutrient digestibility, blood profile, gut morphology and histological features of piglets. A total of 48 newly weaned piglets were individually weighed (initial body weight (IBW): $6.1 \pm 0.16 \mathrm{~kg}$ ) and randomly allocated to 3 dietary treatments ( 4 boxes as replicates/treatment and 4 animals/box). BSF larva meal was included at increasing levels (0\% [BSF0], 5\% [BSF5] and 10\% [BSF10]) in isonitrogenous and isoenergetic diets formulated for two feeding phases: I (from d 1 to $\mathrm{d} 23$ ) and II (from d 24 to $\mathrm{d}$ 61). The weight gain $(W G)$, average daily gain (ADG), average daily feed intake (ADFI) and feed conversion ratio (FCR) were calculated for each feeding phase and for the whole trial. The haematochemical parameters and nutrient digestibility of the piglets were also evaluated. A total of 3 piglets per box were slaughtered on $\mathrm{d} 61$ and the slaughtered piglets were submitted to morphometric investigations and histopathological examinations.

Results: No overall significant differences were observed for growth performance $(P>0.05)$, except for the ADFI of phase II, which showed a linear response to increasing BSF meal levels ( $P<0.05$, maximum for the BSF10 group). Dietary BSF meal inclusion did not significantly influence the blood profile, except as far as monocytes and neutrophils are concerned, and these showed a linear and quadratic response, respectively, to increasing BSF meal levels $(P<0.05$, maximum for the BSF10 and BSF5 groups, respectively). On the other hand, the nutrient digestibility, gut morphology and histological features were not affected by dietary BSF meal inclusion $(P>0.05)$.

Conclusions: The obtained results show that a partially defatted BSF larva meal can be used as a feed ingredient in diets for weaned piglets without negatively affecting their growth performance, nutrient digestibility, blood profile, gut morphology or histological features.
\end{abstract}

Keywords: Hermetia illucens L., Histopathology, Insect meal, Performance, Weaning pigs

* Correspondence: achille.schiavone@unito.it

2Department of Veterinary Sciences, University of Turin, Largo P. Braccini 2,

10095 Grugliasco, (TO) Turin, Italy

${ }^{3}$ National Research Council, Institute of Science of Food Production, Largo P.

Braccini 2, 10095 Grugliasco, (TO), Italy

Full list of author information is available at the end of the article

(c) The Author(s). 2019 Open Access This article is distributed under the terms of the Creative Commons Attribution 4.0 International License (http://creativecommons.org/licenses/by/4.0/), which permits unrestricted use, distribution, and reproduction in any medium, provided you give appropriate credit to the original author(s) and the source, provide a link to the Creative Commons license, and indicate if changes were made. The Creative Commons Public Domain Dedication waiver (http://creativecommons.org/publicdomain/zero/1.0/) applies to the data made available in this article, unless otherwise stated. 


\section{Background}

A recent FAO forecast has indicated that the world will be inhabited by over 9.5 billion people by 2050 and that animal protein production will have to more than double to meet the increasing food demand [1]. Within the livestock sector, pigs constitute one of the fastest growing sub-sectors. Furthermore, as a result of changes in consumption patterns, the world's pork meat production has increased from 95 to over 130 million tons in the last 15 years, and currently represents the second most consumed meat in the world [2]. Furthermore, it has been estimated that this production will increase by over $40 \%$ by 2050 [1]. Soybean meal (SBM) is the most frequently used protein source for pig compound feeds, with a recorded global world production of about 300 million tons in 2016 [3]. Compound feeds play a primary role in the world's livestock production, with an overall annual amount of about 1 billion tons [4]. Plant proteins (e.g. SBM), fishmeal and other processed animal proteins have been used extensively in compounds feeds. However, these conventional sources are no longer considered sustainable and are limited by European regulations and/or increasing prices [5]. Therefore, a crucial challenge for future years is the discovery of new and sustainable protein sources for animal feeds.

Insects are one of the most promising novel protein sources [6-8], since they are rich in proteins and have an adequate amino acid profile, lipids and other valuable nutrients such as vitamins and minerals [6]. Moreover, it has been claimed that they are highly sustainable, as some species can be mass reared in organic streams at a much lower environmental cost than conventional protein sources $[9,10]$, thus exalting the concept of Circular Economy. Among the various suitable insects, black soldier fly (BSF) (Hermetia illucens L., HI) is one of the most promising species. It is a cosmopolitan and worldwide Diptera that belongs to the Stratiomyidae family [11]. BSF larvae can be reared on several organic substrates $[12,13]$ and can provide high-value meal that is rich in nutrients when processed [6]. Research on insect meals as animal feeds has increased rapidly, with promising results having been observed for poultry [14-16] and fish [17-19]. Dietary insect meal inclusion for pigs has also attracted increasing interest, with the authors' attention being focused on growth performance [20-25], nutrient digestibility $[23,25,26]$ and blood profile modifications [22, 23]. Recent studies have also investigated the potential gut health implications [24, 25] of using insects in swine diets, as a consequence of the increasing importance of this research topic in animal nutrition [27]. Within this scenario, insects could be particularly advantageous as a novel feed additive to improve gut health, because of the immune-system stimulating properties of chitin [28] and of the antibacterial/microbial activity of antimicrobial peptides [29] and lauric acid [25].
Spranghers et al. [25] have recently reported gut antimicrobial effects and unaffected gut morphology in weaned piglets fed BSF prepupae, but no information related to BSF larva utilization is currently available. Furthermore, there is still a lack of data about the potential diet-related, histopathological changes of organs that could be added to the knowledge on blood parameters in animal health assessments.

On the basis of the above reported background, the present study has been aimed at evaluating the effects of a partially defatted BSF larva meal on the growth performance, nutrient digestibility, blood profile, gut morphology and histological features of piglets, in order to increase knowledge and provide novel information on the potential use of insect meal in pig nutrition.

\section{Methods}

The present trial was carried out at the Teaching Structure of Veterinary Medicine of the University of Turin (Italy).

\section{BSF larva meal and experimental diets}

A partially defatted BSF larva meal, obtained by processing larvae reared on a vegetable by-products substrate, was purchased from Hermetia Deutschland GmbH \& Co. KG (Baruth / Mark, Germany) and used in the trial. The BSF larva meal was partially defatted by means of a mechanical process which was performed using high pressure and without any solvents. No other information was provided by the producer regarding the substrate or processing methodologies, as this information is considered confidential. A total of 3 experimental diets were formulated to have the same net energy (NE) and crude protein (CP) levels. The diets for each dietary treatment were divided into 2 phases: phase I (days of trial: 1 to 23) and phase II (days of trial: 24 to 61 ). The diets were prepared to include, on a feed basis, increasing levels of BSF larva meal in substitution of $0,30 \%$ and $60 \%$ (BSF0, BSF5 and BSF10, respectively) of SBM (Phase I) or 0, 32\% and 65\% (BSF0, BSF5 and BSF10, respectively) of SBM (Phase II). The diets were formulated to meet the nutrient requirements of piglets [30]. An aliquot of $0.5 \%$ of titanium oxide $\left(\mathrm{TiO}_{2}\right.$ - Nova Chimica Srl) was added to all the diets to determine the nutrient digestibility at the end of the two feeding phases, using the index method reported by Zhang and Adeola [31]. Feed and fresh water were provided ad libitum. The ingredients of the experimental diets and their relative inclusion levels are reported in Table 1.

\section{Chemical analyses of BSF larva meal and experimental diets}

The BSF larva meal and the experimental diets were ground using a cutting mill (MLI 204; Bühler AG, Uzwil, Switzerland) and analysed to establish the dry matter (DM; AOAC\# 934.01), CP (AOAC\# 984.13), acid detergent fiber 
Table 1 Ingredients, proximate composition and net energy of the BSF larva meal and experimental diets

\begin{tabular}{|c|c|c|c|c|c|c|c|}
\hline \multirow[t]{2}{*}{ Items } & \multirow{2}{*}{$\begin{array}{l}\text { BSF larva } \\
\text { meal }\end{array}$} & \multicolumn{3}{|c|}{ Phase I (1-23d) } & \multicolumn{3}{|c|}{ Phase II (24-61 d) } \\
\hline & & $\overline{B S F 0}$ & BSF5 & $\overline{B S F 10}$ & $\overline{B S F 0}$ & BSF5 & BSF10 \\
\hline \multicolumn{8}{|l|}{ Ingredients, $\mathrm{g} / \mathrm{kg}$ as fed } \\
\hline Corn meal & - & 317.9 & 332.7 & 347.3 & 378.0 & 392.9 & 407.4 \\
\hline Barley meal & - & 220.0 & 220.0 & 220.0 & 220.0 & 220.0 & 220.0 \\
\hline Soybean meal & - & 200.0 & 140.0 & 80.0 & 185.0 & 125.0 & 65.0 \\
\hline Dried whey ${ }^{a}$ & - & 140.0 & 140.0 & 140.0 & 100.0 & 100.0 & 100.0 \\
\hline Wheat meal & - & 60.0 & 60.0 & 60.0 & 60.0 & 60.0 & 60.0 \\
\hline Soybean oil & - & 25.0 & 21.0 & 17.0 & 20.0 & 16.0 & 12.0 \\
\hline BSF meal ${ }^{\mathrm{b}}$ & - & 0.0 & 50.0 & 100.0 & 0.0 & 50.0 & 100.0 \\
\hline Calcium carbonate & - & 6.0 & 7.5 & 8.0 & 7.0 & 8.5 & 10.0 \\
\hline L-lysine & - & 6.5 & 7.1 & 7.6 & 5.5 & 6.0 & 6.6 \\
\hline Titanium oxide & - & 5.0 & 5.0 & 5.0 & 5.0 & 5.0 & 5.0 \\
\hline Premix piglets ${ }^{c}$ & - & 5.0 & 5.0 & 5.0 & 5.0 & 5.0 & 5.0 \\
\hline Dicalcium phosphate & - & 5.0 & 3.0 & 0.0 & 6.0 & 3.0 & 0.0 \\
\hline$D L$-methionine & - & 3.0 & 3.0 & 3.2 & 2.4 & 2.4 & 2.6 \\
\hline Salt & - & 2.5 & 2.5 & 2.5 & 2.5 & 2.5 & 2.5 \\
\hline L-threonine & - & 2.5 & 2.6 & 2.8 & 2.0 & 2.1 & 2.3 \\
\hline L-tryptophan & - & 0.8 & 0.8 & 0.8 & 0.8 & 0.8 & 0.8 \\
\hline Pig aroma & - & 0.8 & 0.8 & 0.8 & 0.8 & 0.8 & 0.8 \\
\hline \multicolumn{8}{|c|}{ Proximate composition, $\mathrm{g} / \mathrm{kg}$ as $\mathrm{fed}^{\mathrm{d}}$} \\
\hline DM & 947.4 & 899.8 & 903.1 & 906.4 & 894.0 & 897.3 & 900.7 \\
\hline Ash & 76.7 & 47.2 & 46.4 & 45.5 & 46.1 & 45.3 & 44.6 \\
\hline $\mathrm{CP}$ & 559.0 & 178.8 & 178.9 & 179.0 & 170.4 & 170.4 & 170.6 \\
\hline $\mathrm{EE}$ & 85.0 & 73.5 & 73.4 & 73.3 & 61.9 & 61.8 & 61.7 \\
\hline Starch & - & 346.8 & 354.3 & 361.7 & 384.2 & 391.8 & 399.1 \\
\hline NDF & 192.3 & 109.8 & 115.2 & 120.7 & 114.2 & 119.6 & 125.1 \\
\hline ADF & 87.0 & 40.5 & 42.1 & 43.6 & 41.4 & 43.0 & 44.5 \\
\hline Chitin & 53.4 & - & - & - & - & - & - \\
\hline $\mathrm{NE}, \mathrm{MJ} / \mathrm{kg}$ & - & 10.6 & 10.6 & 10.6 & 10.4 & 10.3 & 10.3 \\
\hline Calcium & 8.2 & 5.1 & 5.1 & 5.2 & 5.5 & 5.6 & 5.6 \\
\hline Phosphorus & 13.1 & 5.1 & 4.9 & 4.9 & 5.1 & 4.9 & 4.7 \\
\hline Magnesium & 4.5 & 1.7 & 1.8 & 1.8 & 1.7 & 1.8 & 1.8 \\
\hline Sodium & 1.1 & 2.1 & 2.1 & 2.2 & 1.8 & 1.8 & 1.9 \\
\hline Potassium & 18.7 & 10.1 & 9.6 & 9.1 & 9.2 & 8.7 & 8.2 \\
\hline Chlorine & 4.3 & 5.2 & 5.5 & 5.8 & 4.5 & 4.8 & 5.1 \\
\hline Manganese, mg/kg & 203.0 & 66.8 & 75.2 & 83.5 & 66.8 & 75.1 & 83.5 \\
\hline Zinc, mg/kg & 172.0 & 128.6 & 134.1 & 139.7 & 129.2 & 134.6 & 140.1 \\
\hline Iron, mg/kg & 154.0 & 184.7 & 178.4 & 174.1 & 186.6 & 180.3 & 174.0 \\
\hline \multicolumn{8}{|c|}{ Essential amino acids, g/kg as fed ${ }^{d}$} \\
\hline Methionine & 7.3 & 5.5 & 5.5 & 5.7 & 4.9 & 4.8 & 5.0 \\
\hline Methione + Cysteine & 12.0 & 8.4 & 8.2 & 8.3 & 7.7 & 7.5 & 7.5 \\
\hline Lysine & 26.6 & 14.0 & 14.0 & 13.9 & 12.6 & 12.5 & 12.5 \\
\hline Threonine & 20.1 & 9.0 & 9.0 & 9.1 & 8.2 & 8.2 & 8.2 \\
\hline Arginine & 25.6 & 10.3 & 9.4 & 8.6 & 9.9 & 9.0 & 8.2 \\
\hline
\end{tabular}


Table 1 Ingredients, proximate composition and net energy of the BSF larva meal and experimental diets (Continued)

\begin{tabular}{|c|c|c|c|c|c|c|c|}
\hline \multirow[t]{2}{*}{ Items } & \multirow{2}{*}{$\begin{array}{l}\text { BSF larva } \\
\text { meal }\end{array}$} & \multicolumn{3}{|c|}{ Phase I (1-23 d) } & \multicolumn{3}{|c|}{ Phase II (24-61 d) } \\
\hline & & BSF0 & BSF5 & BSF10 & BSF0 & BSF5 & BSF10 \\
\hline Valine & 21.9 & 8.0 & 8.1 & 8.2 & 7.6 & 7.8 & 7.9 \\
\hline Tryptophan & 34.8 & 2.9 & 2.9 & 2.8 & 2.8 & 2.7 & 2.7 \\
\hline Isoleucine & 30.2 & 7.1 & 6.8 & 6.6 & 6.7 & 6.5 & 6.2 \\
\hline Leucine & 14.4 & 13.7 & 13.2 & 12.7 & 13.3 & 12.8 & 12.4 \\
\hline Histidine & 31.3 & 4.3 & 4.2 & 4.2 & 4.1 & 4.1 & 4.0 \\
\hline Phenylalanine & 7.3 & 8.2 & 8.2 & 8.3 & 7.9 & 7.9 & 8.0 \\
\hline
\end{tabular}

$B S F$ black soldier fly; $D M$ dry matter; $C P$ crude protein; $E E$ ether extract; $N D F$ neutral detergent fiber; $A D F$ acid detergent fiber; $N E$ net energy; $B S F O=$ control diet; $B S F 5=5 \%$ inclusion level of black soldier fly meal; $B S F 10=10 \%$ inclusion level of black soldier fly meal

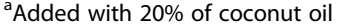

${ }^{\mathrm{b}}$ Black soldier fly larva meal purchased from Hermetia Deutschland GmbH \& Co. KG (Baruth / Mark, Germany)

'Premix: $16,000 \mathrm{IU}$ vitamin $\mathrm{A} ; 2,000 \mathrm{IU}$ vitamin $\mathrm{D}_{3} ; 75.0 \mathrm{mg}$ vitamin $\mathrm{E} ; 2.94 \mathrm{mg}$ vitamin $\mathrm{K}_{3} ; 3.0 \mathrm{mg}$ vitamin $\mathrm{B}_{1} ; 6.0 \mathrm{mg}$ vitamin $\mathrm{B}_{2} ; 4.0 \mathrm{mg}$ vitamin $\mathrm{B}_{6} ; 0.05 \mathrm{mg}$ vitamin $\mathrm{B}_{12} ; 98 \mathrm{mg}$ vitamin $\mathrm{C} ; 21.0 \mathrm{mg}$ pantothenic acid; $40.0 \mathrm{mg}$ vitamin PP; $1.20 \mathrm{mg}$ folic acid; $0.25 \mathrm{mg}$ biotin; 1,500 IU 6-phytase; $700 \mathrm{IU}$ xylanase; $312.5 \mathrm{IU}$ glucanase; $145.68 \mathrm{mg}$ copper; $0.05 \mathrm{mg}$ cobalt; $0.44 \mathrm{mg}$ selenium

${ }^{d}$ Values are reported as mean of duplicate analyses

(ADF; AOAC\# 973.18) and ash (AOAC\# 942.05) contents according to AOAC International [32]. The ether extract (EE; AOAC\# 2003.05) was analysed according to AOAC International [33]. The neutral detergent fiber (NDF) was analysed according to Van Soest et al. [34]; $\alpha$-amylase (Sigma Aldrich, Saint Louis, MO, USA) was added, but no sodium sulphite, and the results were corrected for the residual ash content. All the analyses were performed in duplicate. The NE values of the diets were calculated according to Noblet et al. [35]. The amount of chitin of the BSF meal was estimated according to Finke [36]. Diet samples were prepared using a 22-h hydrolysis step in 6 $\mathrm{mol} / \mathrm{L} \mathrm{HCl}$ at $112^{\circ} \mathrm{C}$ under a nitrogen atmosphere to determine amino acids (AA). Performic acid oxidation occurred prior to acid hydrolysis for methionine and cysteine. The AA in the hydrolysate were determined by means of HPLC, after post-column derivatization, according to the procedure described by Madrid et al. [37]. The proximate composition and NE of the BSF larva meal and of the experimental diets are shown in Table 1.

\section{Growth performance}

A total of 48 commercial piglets (females, Topigs) were weaned at $20 \pm 1$ days of age, individually weighed (initial body weight [IBW]: $6.1 \pm 0.16 \mathrm{~kg}$ ) and randomly allotted to the 3 previously described dietary treatments. Each diet was replicated in 4 boxes of 4 piglets with a homogeneous IBW per box. The piglets - all identified with ear tags were individually weighed at $\mathrm{d} 23$ (feed change from phase I to phase II) and at the end of the trial (d 61). The trial lasted $40 \mathrm{~d}$. The weight gain (WG), average daily gain (ADG), average daily feed intake (ADFI) and feed conversion ratio (FCR) were calculated for each feeding phase and for the whole experimental period. Mortality was checked daily and calculated as: (number of dead pigs / number of pigs at start) $\times 100$.

\section{Nutrient digestibility}

Faeces were collected for 4 consecutive days, twice a day (09:00 and 15:00). Sampling was conducted in each box for 2 consecutive hours (from 09:00 to 11:00 and from 15:00 to $17: 00)$ as soon as the faeces were released by the piglets. The faeces of each sampling moment were pooled per box and immediately stored at $-18^{\circ} \mathrm{C}$. The feces samples were dried at $60^{\circ} \mathrm{C}$ for $72 \mathrm{~h}$, finely ground and pooled per box in equal proportions. Samples were analysed for DM, CP and EE, according to the AOAC methodologies described for feed analysis. The diet and feces samples were analysed to establish the $\mathrm{TiO}_{2}$ content using a UV spectrophotometer (UNICAN UV-Vis Spectrometry, Helios Gamma, United Kingdom) according to the method of Short et al. [38].

Using the analysed values for nutrient concentration, as well as the concentration of the $\mathrm{TiO}_{2}$ in the feed and faeces, the nutrient digestibility was calculated as follows: $\mathrm{Di}$ gestibility (\%): $100-[100 \times(\mathrm{Nf} \times \mathrm{Td}) /(\mathrm{Nd} \times \mathrm{Tf})]$ where $\mathrm{Nf}$ and $\mathrm{Nd}$ are the nutrient concentrations (\% DM) in the faeces and diet, respectively, and $\mathrm{Td}$ and $\mathrm{Tf}$ are the $\mathrm{TiO}_{2}$ concentrations (\% $\mathrm{DM})$ in the diets and faeces, respectively.

\section{Blood and serum parameters}

A total of 12 piglets per treatment ( 3 animals per box) were randomly selected and slaughtered in the EC-approved slaughterhouse of SDSV - Teaching Structure of Veterinary Medicine of the University of Turin (Italy) at 61 days of age. The animals were stunned, by electrocution, and exsanguinated. Sterile tubes containing heparin were utilized to collect blood samples for haematological analysis, which was conducted using an automated laser cell counter calibrated for swine (MS4-S Hematology Analyzer, Melet Schloesing, Osny, France). A plain serum tube was instead utilized as a container to obtain serum for biochemistry analysis and protein electrophoresis, which was conducted 
using an automated photometer system (Screen Master Touch, Hospitex Diagnostics, Sesto Fiorentino, Florence, Italy) and a semi-automated agarose gel electrophoresis system (Sebia Hydrasys, Evry, France), respectively.

\section{Slaughter procedures and samples collection}

The slaughtered piglets were submitted to anatomopathological investigations. Intestinal segment samples (approximately $5 \mathrm{~cm}$ in length) were excised and flushed with $0.9 \%$ saline to remove all the content. The collected segments of intestine were the tract after the pylorus (duodenum), the mid jejunum (jejunum) and the tract before the ileocecal junction (ileum). Samples of liver, spleen, lung, stomach and kidney were also collected. Gut segments and organs samples were fixed in Carnoy's and 10\% neutral buffered formalin ( $4 \%$ formaldehyde) solutions for morphometric analysis (gut segments) and a histopathological examination (gut segments and organs). Tissues were routinely embedded in paraffin wax blocks, sectioned at $5 \mu \mathrm{m}$ thickness and mounted on glass slides.

\section{Histomorphological investigations}

The Carnoy-fixed and paraffin-embedded intestinal sections were submitted to Haematoxylin \& Eosin staining, and one slide per each intestinal segment was examined by means of light microscopy. Each slide was captured with a Nikon DS-Fi1 digital camera (Nikon Corporation, Minato, Tokyo, Japan), coupled to a Zeiss Axiophot microscope (Carl Zeiss, Oberkochen, Germany), using a $2.5 \times$ objective lens. NIS-Elements F software (Nikon Corporation, Minato, Tokyo, Japan) was used for image capturing. Morphometric analysis was performed by means of Image-Pro Plus software, version 6.0 (Media Cybernetics Inc., Bethesda, Rockville, MD, USA). The evaluated morphometric indices were the villus height ( $\mathrm{Vh}$, from the top of the villus to the villus-crypt junction), crypt depth $(\mathrm{Cd}$, from the villus-crypt junction to the base of the crypt) and the villus height to crypt depth ratio $(\mathrm{Vh} / \mathrm{Cd}$, calculated by dividing the villus height by the crypt depth) [39]. Morphometric measurements were performed on 10 well-oriented and intact villi and on 10 crypts chosen from the duodenum, jejunum and ileum [40].

Formalin-fixed and paraffin-embedded gut segments and organ sections were submitted to Haematoxylin \& Eosin staining and examined by means of light microscopy. The observed histopathological alterations were evaluated using a semiquantitative scoring system as follows: absent (score $=0)$, mild (score $=1)$, moderate $($ score $=2)$ and severe $($ score $=3)$. A single score was given for the histopathological alterations of the liver, spleen, lung, stomach and kidneys, while the gut histopathological findings were assessed separately for the mucosa (inflammatory infiltrates) and submucosa (inflammatory infiltrates and gut-associated lymphoid tissue [GALT] activation) of each segment. The total score of each gut segment was obtained by adding the mucosa and submucosa scores, while the total score of each piglet was represented by the mean value of the duodenum, jejunum and ileum scores. All the slides were blind assessed by 3 observers and the discordant cases were reviewed, using a multi-head microscope, until unanimous consensus was reached.

\section{Statistical analysis}

The data were analysed using the IBM SPSS Statistics V25.0.0 software (SPSS Inc., Chicago, IL, USA). An individual pig was used as the experimental unit to analyse the blood parameters, gut morphology and histological features ( $n=12$ per treatment), while each box was considered as the experimental unit for the growth performance and nutrient digestibility ( $n=4$ per treatment).

The growth performance, nutrient digestibility and blood parameter data were tested by means of one-way analysis of variance (ANOVA), and the effect of dietary BSF meal inclusion was evaluated by means of polynomial contrasts (linear and quadratic). The intestinal morphometric indices were analysed by fitting a general linear mixed model (GLMM). GLMM allowed the morphometric indices ( $\mathrm{Vh}, \mathrm{Cd}$ and $\mathrm{Vh} / \mathrm{Cd}$, separately) to depend on three fixed factors (diet, intestinal segment and the interaction between the diet and intestinal segment). Animal was included as a random effect to account for repeated measurements on the same piglet. The interactions between the levels of the fixed factors were evaluated by means of pairwise comparisons. The histopathological scores were analysed by means of the Kruskal-Wallis test (post-hoc test: Dunn's Multiple Comparison test).

The results were expressed as the mean (growth performance, nutrient digestibility, blood parameter and histopathological data) or least square mean (intestinal morphometric indices) and standard error of the mean (SEM). $P$ values $\leq 0.05$ were considered statistically significant. A statistical trend was considered for $0.05<$ $P \leq 0.10$.

\section{Results \\ Growth performance}

The growth performance parameters of the piglets are summarized in Table 2. The piglets readily accepted the experimental diets, with a survival ranging from 98\% (BSF10) to $100 \%$ (BSF0 and BSF5). Dietary BSF meal inclusion did not significantly influence the growth performance of the animals, except for the ADFI of phase II, which showed a linear response to increasing BSF meal levels $(P<0.05$, with a maximum corresponding to the inclusion of $10 \%$ of BSF meal). 
Table 2 Effects of dietary BSF larva meal inclusion on growth performance of the piglets $(n=4)$

\begin{tabular}{|c|c|c|c|c|c|c|c|}
\hline \multirow[t]{2}{*}{ Items } & & \multicolumn{3}{|c|}{ Dietary treatments } & \multirow[t]{2}{*}{ SEM } & \multicolumn{2}{|l|}{$P$-value } \\
\hline & & BSF0 & BSF5 & BSF10 & & Linear & Quadratic \\
\hline \multirow[t]{3}{*}{$\mathrm{BW}, \mathrm{kg}$} & Initial & 6.10 & 6.09 & 6.09 & 0.005 & 0.620 & 0.621 \\
\hline & End Phase I & 12.06 & 12.00 & 12.34 & 0.191 & 0.576 & 0.643 \\
\hline & End Phase ॥ & 31.88 & 32.23 & 33.06 & 0.457 & 0.708 & 0.587 \\
\hline \multirow[t]{3}{*}{ WG, kg } & Phase I & 5.96 & 5.91 & 6.24 & 0.190 & 0.574 & 0.656 \\
\hline & Phase II & 19.81 & 20.23 & 20.72 & 0.498 & 0.399 & 0.894 \\
\hline & Total & 25.78 & 26.14 & 26.96 & 0.581 & 0.361 & 0.791 \\
\hline \multirow[t]{3}{*}{$A D G, \mathrm{~kg} / \mathrm{d}$} & Phase I & 0.26 & 0.26 & 0.27 & 0.008 & 0.574 & 0.656 \\
\hline & Phase II & 0.52 & 0.53 & 0.55 & 0.013 & 0.399 & 0.894 \\
\hline & Total & 0.42 & 0.43 & 0.44 & 0.010 & 0.361 & 0.791 \\
\hline \multirow[t]{3}{*}{ ADFI, $\mathrm{kg} / \mathrm{d}$} & Phase I & 0.35 & 0.37 & 0.38 & 0.012 & 0.420 & 0.944 \\
\hline & Phase II & 0.94 & 0.95 & 0.97 & 0.005 & 0.016 & 0.709 \\
\hline & Total & 0.72 & 0.73 & 0.75 & 0.006 & 0.069 & 0.922 \\
\hline \multirow[t]{3}{*}{ FCR } & Phase I & 1.35 & 1.42 & 1.41 & 0.030 & 0.578 & 0.479 \\
\hline & Phase II & 1.81 & 1.79 & 1.76 & 0.038 & 0.718 & 0.976 \\
\hline & Total & 1.71 & 1.70 & 1.70 & 0.033 & 0.848 & 0.888 \\
\hline
\end{tabular}

BSF black soldier fly; $B W$ body weight; $W G$ weight gain; $A D G$ average daily gain; $A D F I$ average daily feed intake; $F C R$ feed conversion ratio; SEM standard error of the mean; $B S F O=$ control diet; $B S F 5=5 \%$ inclusion level of black soldier fly meal; BSF $10=10 \%$ inclusion level of black soldier fly meal

\section{Nutrient digestibility}

Dietary BSF meal inclusion did not significantly affect the piglets' digestibility of the diets (Table 3 ).

\section{Blood and serum parameters}

The blood and serum parameters of the piglets are shown in Tables 4 and 5. Dietary BSF meal inclusion did not significantly influence the haematochemical profile or serum protein electrophoresis of the animals, except for the monocytes and neutrophils, which showed a

Table 3 Effects of dietary BSF larva meal inclusion on nutrient digestibility in the piglets ( $n=4$, end of both feeding phases)

\begin{tabular}{|c|c|c|c|c|c|c|c|}
\hline \multirow[t]{2}{*}{ Items } & & \multicolumn{3}{|c|}{ Dietary treatments } & \multirow[t]{2}{*}{ SEM } & \multicolumn{2}{|l|}{$P$-value } \\
\hline & & BSF0 & BSF5 & BSF10 & & Linear & Quadratic \\
\hline \multirow[t]{2}{*}{$\mathrm{DM}$} & Phase I & 0.960 & 0.955 & 0.959 & 0.003 & 0.924 & 0.503 \\
\hline & Phase II & 0.958 & 0.954 & 0.958 & 0.003 & 0.926 & 0.534 \\
\hline \multirow[t]{2}{*}{ OM } & Phase I & 0.965 & 0.960 & 0.964 & 0.003 & 0.857 & 0.524 \\
\hline & Phase II & 0.964 & 0.960 & 0.964 & 0.003 & 0.913 & 0.518 \\
\hline \multirow[t]{2}{*}{ CP } & Phase I & 0.803 & 0.808 & 0.828 & 0.012 & 0.443 & 0.805 \\
\hline & Phase II & 0.766 & 0.777 & 0.795 & 0.015 & 0.466 & 0.916 \\
\hline \multirow[t]{2}{*}{ EE } & Phase I & 0.811 & 0.857 & 0.856 & 0.014 & 0.220 & 0.442 \\
\hline & Phase ॥ & 0.853 & 0.828 & 0.865 & 0.012 & 0.716 & 0.291 \\
\hline
\end{tabular}

$B S F$ black soldier fly; $D M$ dry matter; $O M$ organic matter; $C P$ crude protein; $E E$ ether extract; SEM standard error of the mean; $B S F O=$ control diet; $B S F 5=5 \%$ inclusion level $5 \%$ inclusion level of black soldier fly meal; BSF10 $=10 \%$ inclusion level of black soldier fly meal linear and quadratic response, respectively, to increasing BSF meal levels $(P<0.05$, with the maximum corresponding to the inclusion of $10 \%$ and $5 \%$ of BSF meal, respectively).

\section{Histomorphological investigations}

The effects of the diet, intestinal segment and interaction between the diet and intestinal segment on the intestinal morphometric indices of the piglets are summarized in Table 6. The intestinal segment significantly affected Vh, $\mathrm{Cd}$ and $\mathrm{Vh} / \mathrm{Cd}(P<0.001, P<0.05$ and $P<0.01$, respectively). The duodenum and jejunum showed higher $\mathrm{Vh}$ and Vh/Cd $(P<0.01$ and $P<0.05$, respectively) than the ileum, while a greater $\mathrm{Cd}(P<0.05)$ was observed in the duodenum than in the other gut segments. On the contrary, there was no influence of diet or interaction between the diet and intestinal segment on the morphometric indices.

Histopathological alterations developed in the stomach, gut, liver and kidneys of the piglets for all the dietary treatments (Fig. 1). On the contrary, the spleen and lung showed no alterations. The stomach and gut showed mucosal/submucosal lymphoplasmacytic or eosinophilic inflammation, with or without GALT activation. Vacuolar degeneration of the hepatocytes and lymphoplasmacytic inflammation with or without fibrous tissue deposition was observed in the liver. Finally, interstitial lymphoplasmacytic inflammation and tubular steatosis were identified in the kidneys. However, dietary BSF meal inclusion did not affect the severity of the observed histopathological alterations (Table 7).

\section{Discussion}

\section{Growth performance}

Overall, dietary BSF meal inclusion did not influence the growth performance of the piglets involved in the present study, although an increasing ADFI was identified in phase II for increasing levels of BSF meal inclusion. This could be attributed to an increased diet palatability, related to insect meal inclusion, as already reported by Jin et al. [23]. Furthermore, the higher feed assumption was only observed in the second phase of the trial, thus suggesting a potential tendency of piglets to eat the insect-based diets. However, the overall growth performance observed in the current research is in agreement with Driemeyer [22], who showed no effects for the growth performance of piglets fed maize-soybean and fish meal-based diets in which the full-fat BSF inclusion level was 3.5\% in partial substitution of fish meal. Similarly, Spranghers et al. [25] have recently observed no effect on the growth performance of weaned piglets fed diets including full-fat (4\% and $8 \%$ ) and defatted (5.4\%) BSF prepupae. More heterogeneous results were previously reported, when other insect larvae were used as protein sources in swine feeds. In fact, piglets fed diets in which HI replaced $75 \%$ of SBM tended to show a slightly 
Table 4 Effects of dietary BSF larva meal inclusion on haematochemical parameters of the piglets $(n=12$, end of the trial)

\begin{tabular}{|c|c|c|c|c|c|c|}
\hline \multirow[t]{2}{*}{ Items } & \multicolumn{3}{|c|}{ Dietary treatments } & \multirow[t]{2}{*}{ SEM } & \multicolumn{2}{|c|}{$P$-value } \\
\hline & BSFO & BSF5 & BSF10 & & Linear & Quadratic \\
\hline White blood cells, $10^{6} / \mathrm{mm}^{3}$ & 13.10 & 14.99 & 14.85 & 0.869 & 0.435 & 0.591 \\
\hline Lymphocytes, \% & 55.73 & 50.13 & 60.24 & 2.167 & 0.368 & 0.086 \\
\hline Monocytes, \% & 3.92 & 4.00 & 4.78 & 0.167 & 0.033 & 0.305 \\
\hline Neutrophils, \% & 36.16 & 41.72 & 26.12 & 2.485 & 0.076 & 0.035 \\
\hline Eosinophils, \% & 3.81 & 3.78 & 8.39 & 0.801 & 0.078 & 0.299 \\
\hline Basophils, \% & 0.382 & 0.383 & 0.30 & 0.041 & 0.421 & 0.630 \\
\hline Red blood cells, $10^{6} / \mathrm{mm}^{3}$ & 7.57 & 7.69 & 7.89 & 0.306 & 0.681 & 0.953 \\
\hline$M C V, f L$ & 57.35 & 57.23 & 57.40 & 0.354 & 0.948 & 0.849 \\
\hline Haematocrit, \% & 43.43 & 43.91 & 45.47 & 1.812 & 0.658 & 0.892 \\
\hline $\mathrm{MCH}, \mathrm{pg}$ & 18.17 & 18.76 & 19.35 & 0.366 & 0.204 & 0.997 \\
\hline $\mathrm{MCHC}, \mathrm{g} / \mathrm{dL}$ & 31.78 & 32.90 & 33.90 & 0.687 & 0.224 & 0.968 \\
\hline RDW, fL & 14.13 & 14.15 & 14.15 & 0.159 & 0.956 & 0.974 \\
\hline Haemoglobin, g/dL & 13.81 & 14.39 & 14.77 & 0.562 & 0.506 & 0.932 \\
\hline Platelets, $10^{6} / \mathrm{mm}^{3}$ & 197.18 & 195.00 & 181.42 & 11.946 & 0.602 & 0.827 \\
\hline$M P V, f L$ & 11.98 & 11.74 & 12.10 & 0.081 & 0.518 & 0.081 \\
\hline Procalcitonin, \% & 0.24 & 0.23 & 0.22 & 0.015 & 0.598 & 0.978 \\
\hline PDW, fL & 8.56 & 8.14 & 7.81 & 0.323 & 0.366 & 0.955 \\
\hline GOT, IU/L & 111.21 & 126.78 & 143.31 & 12.808 & 0.324 & 0.986 \\
\hline GPT, IU/L & 59.73 & 63.15 & 55.38 & 2.068 & 0.380 & 0.206 \\
\hline$A L P, I U / L$ & 28.52 & 31.19 & 60.49 & 5.952 & 0.082 & 0.880 \\
\hline GGT, IU/L & 43.49 & 48.30 & 40.26 & 2.463 & 0.589 & 0.223 \\
\hline Total protein, g/dL & 6.67 & 6.02 & 5.98 & 0.194 & 0.163 & 0.460 \\
\hline Phosphorus, mg/dL & 14.65 & 17.10 & 14.94 & 0.966 & 0.929 & 0.272 \\
\hline Iron, $\mu \mathrm{g} / \mathrm{dL}$ & 118.39 & 146.99 & 130.32 & 8.975 & 0.617 & 0.242 \\
\hline Magnesium, mEq/L & 1.65 & 2.09 & 1.93 & 0.116 & 0.335 & 0.230 \\
\hline Uric acid, mg/dL & 1.66 & 3.03 & 2.71 & 0.576 & 0.481 & 0.502 \\
\hline Cholesterol, mg/dL & 52.31 & 55.41 & 51.30 & 2.647 & 0.869 & 0.533 \\
\hline Triglycerides, mg/dL & 58.93 & 47.94 & 55.28 & 4.444 & 0.764 & 0.342 \\
\hline Creatinine, mg/dL & 1.44 & 1.68 & 1.61 & 0.058 & 0.242 & 0.212 \\
\hline
\end{tabular}

BSF Black soldier fly; MCV mean corpuscular volume; $M C H$ mean corpuscular haemoglobin; $M C H C$ mean corpuscular haemoglobin concentration; $R D W$ red blood cell distribution width; MPV mean platelet volume; PDW platelet distribution width; GOT glutamic oxaloacetic transaminasi; GPT glutamate-pyruvate transaminasi; $A L P$ alkaline phosphatase; GGT gamma-glutamyl transferase; SEM standard error of the mean. $B S F O=$ control diet; $B S F 5=5 \%$ inclusion level $5 \%$ inclusion level of black soldier fly meal; $B S F 10=10 \%$ inclusion level of black soldier fly meal

lower growth, feed intake and feed and protein conversion ratio than those fed a control diet [24]. Jin et al. [23] also found an improved growth performance in weaning pigs fed corn-soybean meal-based diets in which increasing levels of a full-fat Tenebrio molitor (TM) larva meal (from $1.5 \%$ to $6.0 \%$ ) was used to partially replace soybean meal and soy oil, and they attributed this outcome to an increased palatability of yellow mealworm. Chen et al. [41] also observed similar results for increasing dietary TM protein concentrates of up to $6 \%$. Improved weight gain was also found in weaning pigs fed Musca domestica (L.) [42] and Bombyx mori (L.) [43] meal inclusion diets. On the other hand, dietary house-fly larva meal inclusion has not been reported to influence the growth performance of sows and their offspring [20] or early weaned piglets [21]. The heterogeneity of the results obtained from these previous studies may be related to the nutritive value of the insect meal that was used, which could have been influenced by the species, the insect life stage (adult, larva or pupa) and the insect rearing substrate [7].

\section{Nutrient digestibility}

Dietary BSF meal inclusion did not influence the nutrient digestibility of the piglets in the present study. This result is in agreement with the results of Spranghers et al. [25], who observed a similar apparent total tract 
Table 5 Effects of dietary BSF larva meal inclusion on serum protein electrophoresis of the piglets ( $n=12$, end of the trial)

\begin{tabular}{|c|c|c|c|c|c|c|}
\hline \multirow[t]{2}{*}{ Items } & \multicolumn{3}{|c|}{$\underline{\text { Dietary treatments }}$} & \multirow[t]{2}{*}{ SEM } & \multicolumn{2}{|l|}{$P$-value } \\
\hline & BSFO & BSF5 & BSF10 & & Linear & Quadratic \\
\hline Albumin, \% & 45.73 & 46.41 & 47.50 & 0.372 & 0.056 & 0.789 \\
\hline Albumin, g/dL & 3.07 & 2.79 & 2.84 & 0.092 & 0.335 & 0.398 \\
\hline Alpha globulin, \% & 25.00 & 25.63 & 25.01 & 0.280 & 0.988 & 0.307 \\
\hline Alpha globulin, g/dL & 1.67 & 1.55 & 1.50 & 0.054 & 0.209 & 0.746 \\
\hline Beta globulin, \% & 17.02 & 16.43 & 16.41 & 0.186 & 0.198 & 0.467 \\
\hline Beta globulin, g/dL & 1.13 & 0.99 & 0.98 & 0.033 & 0.080 & 0.307 \\
\hline Gamma globulin, \% & 12.26 & 11.53 & 11.08 & 0.381 & 0.227 & 0.868 \\
\hline Gamma globulin, g/dL & 0.80 & 0.70 & 0.66 & 0.034 & 0.106 & 0.673 \\
\hline
\end{tabular}

$B S F$ black soldier fly; SEM standard error of the Smean; $B S F O=$ control diet; $B S F 5=5 \%$ inclusion level $5 \%$ inclusion level of black soldier fly meal; $B S F 10=$ $10 \%$ inclusion level of black soldier fly meal

digestibility of nutrients in BSF prepupa- and basal diet-fed weaned piglets. On the contrary, Newton et al. [26] reported lower DM and higher EE digestibility in piglets fed 33\% dried HI larva meal than those fed soybean meal, although the CP digestibility was similar. With regards to other insect species, Jin et al. [23] observed a linear improvement in DM and CP digestibility for increasing levels of dried mealworm in diets for weaning pigs. As already hypothesized for growth performance, these discrepancies may be related to the different insect species and life stages, dietary inclusion levels and fat extraction methods. Furthermore, the heterogeneity of the feed ingredients used in the present and above-mentioned researches does not allow any reliable statement to be made about the effective role of BSF in nutrient digestibility modifications. However, the identification of unaffected or even improved nutrient digestibility may reflect a species-specific ability of chitin digestion, as suggested by the high distribution and activity of chitinase [44] and positive selection of chitinase genes [45] previously reported in pigs. Feeding chito-oligosaccharide to weaning piglets has also been reported to improve DM and crude fat digestibility [46]. Finally, no data about organic matter digestibility have been reported for insect-fed pigs, thus making the values obtained in the present study the first ones available.

\section{Blood and serum parameters}

All the haematochemical parameters recorded for the piglets in the present study fell within the physiological reference intervals reported for swine [47], thus suggesting that the insect meal utilization did not negatively influence the health status of the animals. Moreover, the dietary BSF meal inclusion did not significantly affect the blood and serum traits of the pigs in the current research, although increasing monocytes and neutrophils were identified for increasing levels of BSF meal. This finding appears difficult to explain, since none of the BSF piglets showed any signs of physical distress or inflammatory diseases. However, it is important to underline that the haematological and biochemical profiles of herds have rarely been used in pig veterinary practice. Therefore, further studies are recommended to assess their value as a diagnostic technique [22]. Similar findings, in terms of unaffected blood haematology and biochemical parameters (albumin, calcium, phosphorus, iron, IgA, IgG and IgM), have been observed in piglets fed diets with a full-fat 3.5\% BSF inclusion level [22]. Jin et al. [23] instead reported that the dietary supplementation of up to $6 \%$ of dried full-fat mealworm in weaning pigs decreased blood urea nitrogen and increased the serum insulin-like growth factor. However, no significant effects were observed for the serum IgG and IgA concentrations.

\section{Histomorphological investigations}

Dietary BSF meal inclusion did not influence the gut morphology of the piglets in the present study. This result is in agreement with that of Spranghers et al. [25], who observed no effect on the jejunal morphology of BSF prepupa-fed weaned piglets. It is well known that integrity of the intestinal structure is required for the maintenance of intestinal nutrition [48]. Furthermore, modifications of gut morphometric features have been reported to determine significant changes in the weight gain of piglets [40, 49-51]. Since both the intestinal morphology and the growth performance of the BSF-fed piglets in the current research were unaffected, it is reasonable to hypothesize that insect meal utilization does not negatively influence gut development or nutrient absorption. Another interesting aspect that should be considered is that, independently of dietary BSF meal inclusion,

Table 6 Intestinal morphometric indices in the piglets in relation to diet and intestinal segment $(n=12$, end of the trial)

\begin{tabular}{|c|c|c|c|c|c|c|c|c|c|c|}
\hline \multirow[t]{2}{*}{ Items } & \multicolumn{3}{|c|}{ Diet (D) } & \multicolumn{3}{|c|}{ Intestinal segment (IS) } & \multirow[t]{2}{*}{ SEM } & \multicolumn{3}{|c|}{$P$-value } \\
\hline & BSF0 & BSF5 & BSF10 & Duodenum & Jejunum & Ileum & & $\bar{D}$ & IS & $D \times 1 S$ \\
\hline $\mathrm{Vh}, \mathrm{mm}$ & 0.38 & 0.36 & 0.38 & $0.41^{\mathrm{a}}$ & $0.38^{\mathrm{a}}$ & $0.34^{\mathrm{b}}$ & 0.012 & 0.371 & $<0.001$ & 0.709 \\
\hline $\mathrm{Cd}, \mathrm{mm}$ & 0.11 & 0.11 & 0.10 & $0.12^{\mathrm{a}}$ & $0.10^{\mathrm{b}}$ & $0.11^{b}$ & 0.003 & 0.256 & 0.009 & 0.999 \\
\hline $\mathrm{Vh} / \mathrm{Cd}$ & 3.47 & 3.35 & 3.72 & $3.64^{\mathrm{a}}$ & $3.71^{\mathrm{a}}$ & $3.19^{b}$ & 0.126 & 0.159 & 0.007 & 0.566 \\
\hline
\end{tabular}

$B S F O=$ control; $B S F 5=5 \%$ inclusion level $5 \%$ inclusion level of black soldier fly meal; $B S F 10=10 \%$ inclusion level of black soldier fly meal; $V h$, villus height; $C d$, crypt depth; $V h / C d$, villus height to crypt depth ratio

The means with different superscript letters $(a, b)$ within the same row per fixed effect (i.e. diet, intestinal segment) differ significantly $(P<0.05)$ 


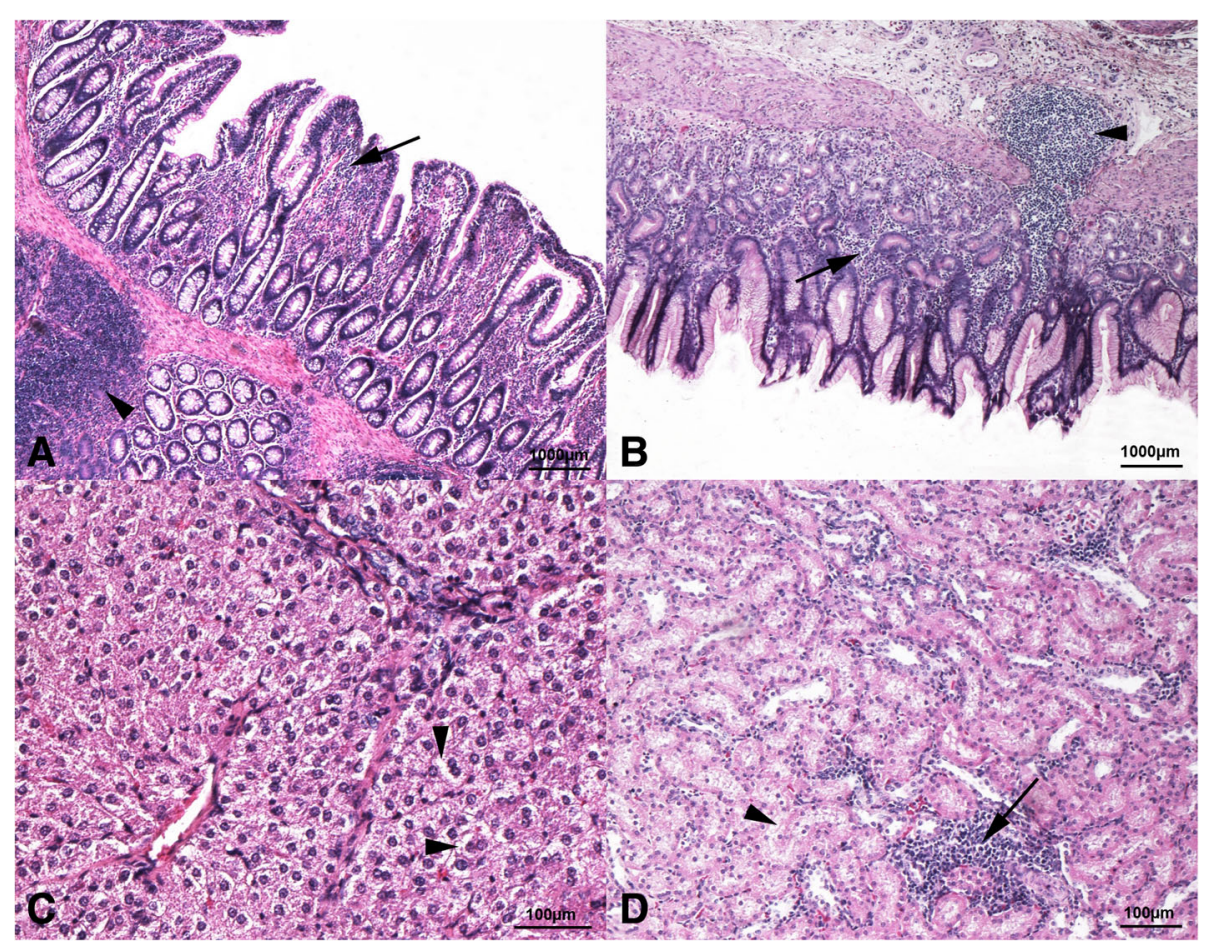

Fig. 1 Histopathological findings of the piglets. a BSF0 group. Mild and multifocal mucosal lymphoplasmacytic inflammation (arrow), as well as focal and moderate gut-associated lymphoid tissue (GALT) activation (arrowhead), are observed in the ileum. $5 \times$ haematoxylin-eosin stain. b BSF5 group. Stomach shows mild and multifocal mucosal lymphoplasmacytic inflammation (arrow) along with focal and moderate GALT activation (arrowhead). 5x haematoxylin-eosin stain. c BSF10 group. Liver, centrolobular zone. Moderate and multifocal vacuolar degeneration of the hepatocytes (arrowheads) is identified. 20x haematoxylin-eosin stain. d BSF0 group. Moderate and multifocal interstitial lymphoplasmacytic inflammation (arrow) and tubular steatosis (arrowhead) are observed in the kidneys. 10x haematoxylin-eosin stain

the duodenum and jejunum showed greater morphometric indices than the ileum. Despite the heterogeneous information about the morphological asset of the different gut segments currently available in literature [52], the identification of higher morphometric values in the duodenum and jejunum appears to be rather constant for pigs $[53,54]$. Therefore, the findings of the present study confirm what was previously reported in literature.

Table 7 Effects of dietary BSF larva meal inclusion on the histopathological scores of the piglets ( $n=12$, end of the trial)

\begin{tabular}{llllll}
\hline Items & BSF0 & BSF5 & BSF10 & SEM & $P$-value \\
\hline Stomach & 1.17 & 1.06 & 1.33 & 0.122 & 0.770 \\
Gut & 2.79 & 3.26 & 3.08 & 0.26 & 0.933 \\
Liver & 0.64 & 0.53 & 0.68 & 0.115 & 0.576 \\
Kidney & 0.82 & 0.96 & 1.00 & 0.064 & 0.381 \\
Spleen & Absence of alterations & & \\
Lung & Absence of alterations & &
\end{tabular}

$B S F$, black soldier fly; SEM, standard error of the mean; $B S F O=$ control diet; $B S F 5=5 \%$ inclusion level $5 \%$ inclusion level of black soldier fly meal; BSF10 $=10 \%$ inclusion level of Black Soldier Fly meal

The data are expressed as the mean of the scores $(0=$ absence of alterations; $1=$ mild alterations; $2=$ moderate alterations; $3=$ severe alterations). The gut scores resulted from the mean of the three gut segments scores (in turn obtained from the adding of the mucosa and submucosa scores)
Dietary BSF meal inclusion did not affect the development or severity of the histopathological alterations in the piglets in the current research. Gastric inflammation was attributed to the sensitiveness of pigs to damage of the gastric mucosa, which frequently occurs as a consequence of stress and feeding practices [55]. An analogous consideration can also be made for gut inflammation. The hepatic and renal alterations varied from mild to moderate and from focal to multifocal in all the pigs, thus suggesting no clinical relevance. Furthermore, no alteration of the serum chemistry was observed in relation to the liver and renal functions.

\section{Conclusions}

The present study suggests that a dietary inclusion of up to $10 \%$ of partially defatted BSF larva meal could be used for weaning pigs without any adverse effects on the growth performance, blood profile, nutrient digestibility, gut morphology or histological features. These results confirm that BSF has the potential to become a valuable source of sustainable proteins in pig nutrition. However, since the price of insects is still not competitive, future studies should be focused on the use of BSF as a potential feed additive to improve the gut health of pigs, in particular through the modulation of the gut microbiota and mucin composition. 


\section{Abbreviations}

AA: Amino acids; ADF: Acid detergent fiber; ADFI: Average daily feed intake; ADG: Average daily gain; ALP: Alkaline phosphatase; BSF: Black soldier fly; BW: Body weight; Cd: Crypt depth; CP: Crude protein; DE: Digestible energy; DM: Dry matter; EE: Ether extract; FBW: Final body weight; FCR: Feed conversion ratio; GGT: Gamma-glutamyl transferase; GOT: Glutamic oxaloacetic transaminase; GPT: Glutamate-pyruvate transaminase; HI: Hermetia illucens; IBW: Initial body weight; MCH: Mean corpuscular haemoglobin; MCHC: Mean corpuscular haemoglobin concentration; MCV: Mean corpuscular volume; MPV: Mean platelet volume; NDF: Neutral detergent fiber; NE: Net energy; PDW: Platelet distribution width; RDW: Red blood cell distribution width; SBM: Soybean meal; SEM: Standard error of the mean; TM: Tenebrio molitor; Vh: Villus height; Vh/ Cd: Villus height to crypt depth ratio; WG: Weight gain

\section{Acknowledgments}

The authors gratefully acknowledge Mr. Dario Sola and Mr. Mario Colombano for technical support and Hermetia Deutschland GmbH \& Co. KG for the provision of the insect meal.

\section{Funding}

Financial support for this work was provided by Martini Group (Premio Iller Campani) and a University of Turin (ex 60\%) grant (Es. fin. 2015-2016-2017).

\section{Availability of data and materials}

The datasets analysed in the present study are available from the corresponding author on reasonable request.

\section{Authors' contributions}

FG, AS and LG conceived and designed the experiment. MR and LG formulated the experimental diets and carried out their analyses. MR, FG, SD, MM, GP, EB, $A D, A S$ and $L G$ prepared the diets and performed the trial. IB, MR, SD, MM, EB, $A D, A S$ and $L G$ collected the experiments data. IB and MTC performed the histomorphometric investigations. SM and ACBL evaluated the nutrients digestibility. SB investigated the blood parameters. IB and MR performed the statistical analysis. All authors interpreted the data. IB, MR and LG wrote the first draft of the manuscript. All authors critically reviewed the manuscript for intellectual content and gave final approval for the version to be published.

\section{Ethics approval and consent to participate}

The experimental protocol was designed according to the guidelines of the current European Directive (2010/63/EU) on the care and protection of animals used for scientific purposes and approved by the Animal Welfare and Ethical Committee of the Department of Veterinary Sciences of the University of Turin (Italy) (Ref. 2, 28/06/2016)

\section{Consent for publication}

Not applicable.

\section{Competing interests}

The authors declare that they have no competing interests.

\section{Author details}

'Department of Agricultural, Forest and Food Sciences, University of Turin, Largo P. Braccini 2, 10095 Grugliasco, (TO), Italy. ²Department of Veterinary Sciences, University of Turin, Largo P. Braccini 2, 10095 Grugliasco, (TO) Turin, Italy. ${ }^{3}$ National Research Council, Institute of Science of Food Production, Largo P. Braccini 2, 10095 Grugliasco, (TO), Italy. ${ }^{4}$ SDSV - Teaching Structure of Veterinary Medicine, University of Turin, Largo P. Braccini 2, 10095 Grugliasco, (TO), Italy. ${ }^{5}$ Department of Animal Production, University of Murcia, Campus de Espinardo, 30071 Murcia, Spain. ${ }^{6}$ Department of Animal and Food Science, Autonomous University of Barcelona, Cerdanyola del Vallès, 08193 Bellaterra, Barcelona, Spain. Feterinary Medical Research Institute for Piemonte, Liguria and the Valle D'Aosta, Via Bologna 148, 10154 Turin, Italy. ${ }^{8}$ Department of Veterinary Medical Sciences, University of Bologna, Via Tolara di Sopra 50, 40064 Ozzano dell'Emilia, (BO), Italy.
Received: 6 November 2018 Accepted: 24 January 2019

Published online: 19 February 2019

\section{References}

1. FAO. Food and Agriculture Organization of the United Nations. World Livestock 2011. Rome: Livestock in Food security; 2011. p. 117.

2. OECD Agriculture Statistics. OECD-FAO Agricultural Outlook (Edition 2018). 2018. https://data.oecd.org/agroutput/meat-consumption.htm. Accessed 03 Dec 2018

3. FAOSTAT. Food and Agriculture Organization of the United Nations Statistics Division. 2016. http://www.fao.org/faostat/en/\#data/QC. Accessed 18 Sep 2018.

4. IFIF. International Feed Industry Federation. 2018. https://ifif.org/global-feed/ industry/. Accessed 18 Sep 2018.

5. Veldkamp T, Bosch G. Insects: a protein-rich feed ingredient in pig and poultry diets. Anim Front. 2015;5:45-50.

6. Makkar HPS, Tran G, Heuzé V, Ankers P. State of the art on use of insects as animal feed. Anim Feed Sci Technol. 2014;197:1-33.

7. Sánchez-Muros MJ, Barroso FG, Manzano-Agugliaro F. Insect meal as renewable source of food for animal feeding: a review. J Clean Prod. 2015; 65:16-27.

8. Henry M, Gasco L, Piccolo G, Fountoulaki E. Review on the use of insects in the diet of farmed fish: past and future. Anim Feed Sci Technol. 2015:203:1-22.

9. Salomone R, Saija G, Mondello G, Giannetto A, Fasulo S, Savastano D. Environmental impact of food waste bioconversion by insects: application of life cycle assessment to process using Hermetia illucens. J Clean Prod. 2017;140:890-905

10. Meneguz M, Schiavone A, Gai F, Dama A, Lussiana C, Renna M, et al. Effect of rearing substrate on growth performance, waste reduction efficiency and chemical composition of black soldier fly (Hermetia illucens) larvae. J Sci Food Agric. 2018a;98:5776-84.

11. Martínez-Sánchez A, Magaña C, Saloña M, Rojo S. First record of Hermetia illucens (Diptera: Stratiomyidae) on human corpses in Iberian Peninsula. Forensic Sci Int 2011;206:e76-8.

12. Meneguz M, Gasco L, Tomberlin JK. Impact of $\mathrm{pH}$ and feeding system on black soldier fly (Hermetia illucens, L; Diptera: Stratiomyidae) larval development. PLoS One. 2018b;13:e0202591.

13. Jucker C, Erba D, Leonardi MG, Lupi D, Savoldelli S. Assessment of vegetable and fruit substrates as potential rearing media for Hermetia illucens (Diptera: Stratiomyidae) larvae. Environ Entomol. 2017:46:1415-23.

14. Biasato I, Gasco L, De Marco M, Renna M, Rotolo L, Dabbou S, et al. Effects of yellow mealworm larvae (Tenebrio molitor) inclusion in diets for female broiler chickens: implications for animal health and gut histology. Anim Feed Sci Technol. 2017;234:253-63.

15. Biasato I, Gasco L, De Marco M, Renna M, Rotolo L, Dabbou S, et al. Yellow mealworm larvae (Tenebrio molitor) inclusion in diets for male broiler chickens: effects on growth performance, gut morphology, and histological findings. Poult Sci. 2018;97:540-8.

16. Dabbou S, Gai F, Biasato I, Capucchio MT, Biasibetti E, Dezzutto D, et al. Black soldier fly defatted meal as a dietary protein source for broiler chickens: effects on growth performance, blood traits, gut morphology and histological features. J Animal Sci Biotechnol. 2018:9:49.

17. Gasco L, Henry M, Piccolo G, Marono S, Gai F, Renna M, et al. Tenebrio molitor meal in diets for European sea bass (Dicentrarchus labrax L.) juveniles: growth performance, whole body composition and in vivo apparent digestibility. Anim Feed Sci Technol. 2016:220:34-45.

18. Renna M, Schiavone A, Gai F, Dabbou S, Lussiana C, Malfatto V, et al. Evaluation of the suitability of a partially defatted black soldier fly (Hermetia illucens L.) larvae meal as ingredient for rainbow trout (Oncorhynchus mykiss Walbaum) diets. J Anim Sci Biotechnol. 2017:8:57.

19. Elia AC, Capucchio MT, Caldaroni B, Magara G, Dörr AJF, Biasato I, et al. Influence of Hermetia illucens meal dietary inclusion on the histological traits, gut mucin composition and the oxidative stress biomarkers in rainbow trout. Aquaculture. 2018;496:50-7.

20. Bayadina GV, Inkina ZG. Effect of prolonged use of housefly larvae in the diet of sows and their offspring on the fattening and meat quality of the young. Nutr Abstr Rev. 1980:52:335.

21. Viroje-Wanasithchaiwat M-S. Effects of fly larval meal grown on pig manure as a source of protein in early weaned pig diets. Thurakit-Ahansat (Thailand). 1989;6:28-31. 
22. Driemeyer H. Evaluation of black soldier fly (Hermetia illucens) larvae as an alternative protein source in pig creep diets in relation to production, blood and manure microbiology parameters. South Africa: Thesis for the degree of master of science, University of Stellenbosch; 2016. p. 114.

23. Jin XH, Heo PS, Hong JS, Kim NJ, Kim YY. Supplementation of dried mealworm (Tenebrio molitor larva) on growth performance, nutrient digestibility and blood profiles in weaning pigs. Asian-Australas J Anim Sci. 2016;29:979-86

24. Velten S, Neumann C, Dorper A, Liebert F. Response of piglets due to amino acid optimization of mixed diets with 75\% replacement of soybeanmeal by partly defatted insect meal (H. illucens). INSECTA 2017. September 7-8, 2017 Berlin, Germany p. 63.

25. Spranghers T, Michiels J, Vrancx J, Ovyn A, Eeckhout M, De Clercq P, et al. Gut antimicrobial effects and nutritional value of black soldier fly (Hermetia illucens L.) prepupae for weaned piglets. Anim Feed Sci Technol. 2018;235: $33-42$.

26. Newton GL, Booram CV, Barker RW, Hale OM. Dried Hermetia Illucens larvae meal as a supplement for swine. J Anim Sci. 1977;44:395-400.

27. Celi P, Cowieson AJ, Fru-Nji F, Steinert RE, Kluenter A-M, Verlha V. Gastrointestinal functionality in animal nutrition and health: new opportunities for sustainable animal production. Anim Feed Sci Technol. 2017;234:88-100

28. van Huis A. Potential of insects as food and feed in assuring food security. Annu Rev Entomol. 2013;58:563-83.

29. Wu Q, Patočka J, Kuča K. Insect antimicrobial peptides, a mini review. Toxins (Basel). 2018;10:461.

30. NRC (National Research Council). Nutrient requirements of swine. 11th ed. Washington, D.C: The National Academy Press; 2012.

31. Zhang F, Adeola $\mathrm{O}$. Techniques for evaluating digestibility of energy, amino acids, phosphorus, and calcium in feed ingredients for pigs. Animal Nutr. 2017;3:344-52

32. AOAC International. Official methods of analysis of AOAC international. 16th ed. Arlington: Association of Official Analytical Chemists; 2000.

33. AOAC International. Official Methods of Analysis of AOAC International. 17th ed. Gaithersburg, MD: Association of Official Analytical Chemists; 2003.

34. Van Soest PJ, Robertson JB, Lewis BA. Methods for dietary fiber, neutral detergent fiber, and nonstarch polysaccharides in relation to animal nutrition. J Dairy Sci. 1991;74:3583-97.

35. Noblet J, Bontems $V$, Tran G. Estimation of the energy value of feeds for pigs. INRA Prod Anim. 2003;16:197-210.

36. Finke MD. Estimate of chitin in raw whole insects. Zoo Biol. 2007;26:105-15.

37. Madrid J, Martínez S, López C, Orengo J, López MJ, Hernández F. Effects of low protein diets on growth performance, carcass traits and ammonia emission of barrows and gilts. Anim Prod Sci. 2013;53:146-53.

38. Short FJ, Gorton P. Wiseman J, Boorman KN. Determination of titanium dioxide added as an inert marker in chicken digestibility studies. Anim Feed Sci Technol. 1996:59:215-21.

39. Almeida W, Nuñez AJ, Schinckel AP, Alvarenga PV, Castelini FR, Silva-Guillen $Y$, et al. Interactive effect of dietary protein and dried citrus pulp levels on growth performance, small intestinal morphology, and hindgut fermentation of weanling pigs. J Anim Sci. 2017;95:257-69.

40. Opheim M, Strube ML, Sterten H, Øverland M, Kjos NP. Atlantic salmon (Salmo salar) protein hydrolysate in diets for weaning piglets - effect on growth performance, intestinal morphometry and microbiota composition. Arch Anim Nutr. 2016:70:44-56.

41. Chen ZB. Analysis for nutritional value of four kinds of insects and use of Tenebrio molitor power in weaning pig production. Shandong: China knowledge resource integrated database (CNKI), Shandong Agricultural University; 2012.

42. Huang ZZ, Zhang NZ. Development of a new source of protein feed rearing maggots. Feed Res. 1984;87:17-21.

43. Zhang JH, Zhou EF. Feed resource and utilization. Beijing: China agriculture press; 2002

44. Jeuniaux C, Cornelius C. Distribution and activity of chitinolytic enzymes in the digestive tract of birds and mammals. Boston: First international conference on Chitin/Chitosan; 1977. p. 542-9.

45. He B, Wang L, Wang J, Li G, Zhang S. Positive selection of three chitinase genes of the family 18 of glycoside hydrolases in mammals. Biologia. 2009; 64:819-25.

46. Han KN, Kwon IK, Lohakare JD, Heo S, Chae BJ. Chito-oligosaccharides as an alternative to antimicrobials in improving performance, digestibility and microbial ecology of the gut in weanling pigs. Asian-Aust J Anim Sci. 2007; 20:556-62.

47. Friendship RM, Lumsden JH, McMillan I, Wilson MR. Hematology and biochemistry reference values for Ontario swine. Can J Comp Med. 1984;48: 390-3.

48. He Q, Ren $\mathrm{P}$, Kong $\mathrm{X}, \mathrm{Xu}$ W, Tang $\mathrm{H}$, Yin $\mathrm{Y}$, et al. Intrauterine growth restriction alters the metabonome of the serum and jejunum in piglets. Mol BioSyst. 2011;7:2147-55.

49. Pluske JR, Thompson MJ, Atwood CS, Bird PH, Williams IH, Hartmann PE. Maintenance of villus height and crypt depth, and enhancement of disaccharide digestion and monosaccharide absorption, in piglets fed on cows' whole milk after weaning. Br J Nutr. 1996;76:409-22.

50. Zijlstra RT, Whang KY, Easter RA, Odle J. Effect of feeding a milk replacer to early-weaned pigs on growth, body composition, and small intestinal morphology, compared with suckled littermates. J Anim Sci. 1996;74:2948-59.

51. Chwen LT, Foo HL, Thanh NT, Choe DW. Growth performance, plasma fatty acids, villous height and crypt depth of preweaning piglets fed with medium chain triacylglycerol. Asian-Australas J Anim Sci. 2013;26:700-4.

52. Al Masri S, Hünigen $\mathrm{H}$, Al Aiyan A, Rieger J, Zentek J, Richardson K, et al. Influence of age at weaning and feeding regimes on the postnatal morphology of the porcine small intestine. J Swine Health Prod. 2015;23: 186-203.

53. Hedemann MS, Eskildsen M, Laerke HN, Pedersen C, Lindberg JE, Laurinen $\mathrm{P}$ et al. Intestinal morphology and enzymatic activity in newly weaned pigs fed contrasting fiber concentrations and fiber properties. J Anim Sci. 2006; 84:1375-86.

54. Rubio LA, Ruiz R, Peinado MJ, Echavarri A. Morphology and enzymatic activity of the small intestinal mucosa of Iberian pigs as compared with a lean pig strain. J Anim Sci. 2010;88:3590-7.

55. Mason F, Pascotto E, Zanfi C, Spanghero M. Effect of dietary inclusion of whole ear corn silage on stomach development and gastric mucosa integrity of heavy pigs at slaughter. Vet J. 2013;198:717-9.

\section{Ready to submit your research? Choose BMC and benefit from:}

- fast, convenient online submission

- thorough peer review by experienced researchers in your field

- rapid publication on acceptance

- support for research data, including large and complex data types

- gold Open Access which fosters wider collaboration and increased citations

- maximum visibility for your research: over $100 \mathrm{M}$ website views per year

At $\mathrm{BMC}$, research is always in progress.

Learn more biomedcentral.com/submissions 